\title{
Static Parameters Influence on Development Effect of Asp Flooding
}

\author{
Yane Wang \\ No1oil product plant, Daqing Oilfield CO.LTD., Petrochina, DaQing Heilongjiang.163111.China
}

Keywords: Asp flooding, Static parameters, Development effect, fluency factor.

\begin{abstract}
The ASP flooding area in daqing oilfield has injected slugs of prerequisite, main slug and the auxiliary slug. As the chemical solution's injected, the difference of effect of well group is obvious. This article comparative analyses the influence of stratum static parameters like effective thickness, permeability, formation coefficient, residual oil, channel sand ratio and so on, in water cut and recovery about the center wells, summarizes the formation static parameters' influence on development effect, provides the basis for oil ASP flooding well group development.
\end{abstract}

\section{Introduction}

In the oil field development, the second reservoir is refers to the effective thickness in 1-4 m, permeability between $100-400 \mu^{2}$, channel sand can't into the development of reservoir. the test area is $3.26 \mathrm{~km} 2$, Purpose reservoir layer is S II 10 - SIII 10, priority with the second kinds of reservoir development, the well pattern is five points area With $125 \mathrm{~m}$, The total number of well is 208. the average single well perforated sandstone thickness is $21.7 \mathrm{~m}$, effective thickness is $13.6 \mathrm{~m}$, central average single well perforated sandstone thickness is $20.9 \mathrm{~m}$, effective thickness is $13.2 \mathrm{~m}$.

\section{The Analysis of Development Effect Factors}

Ultimate goal is EOR of oil recovery, According to the phase recovery grading of the center wells, Contrast analysis the influence of the parameters in 38 central production wells of the test, we find the parameters like the number purpose layer, sandstone thickness, permeability variation coefficient, water cut and recovery degree before it put into production at the beginning, influences on chemical flooding oil phase Recovery degree has obvious regularity. Concrete analysis as follows:

\subsection{The Influence of the Number Purpose Layer}

According the change of layers-water cut line, the less of the layer number, the more obvious of water drop and Chemical flooding effect, Even appears a significant secondary effect phenomenon. but according the Recovery degree line, Layer in 10-20 well recovery degree is higher

The reason: first is the less of layer number, the more conducive to the development adjustment; second is the less of layer number means the Reservoir is poor, it is difficult to production, and lower the Recovery degree

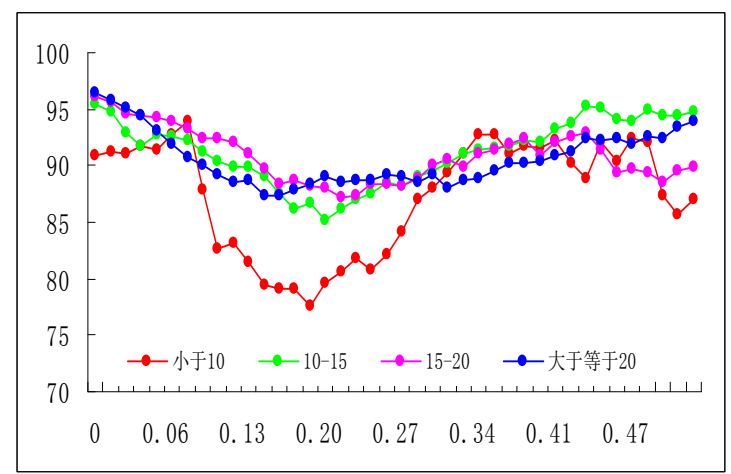

Fig.1 Layers-water cut line 


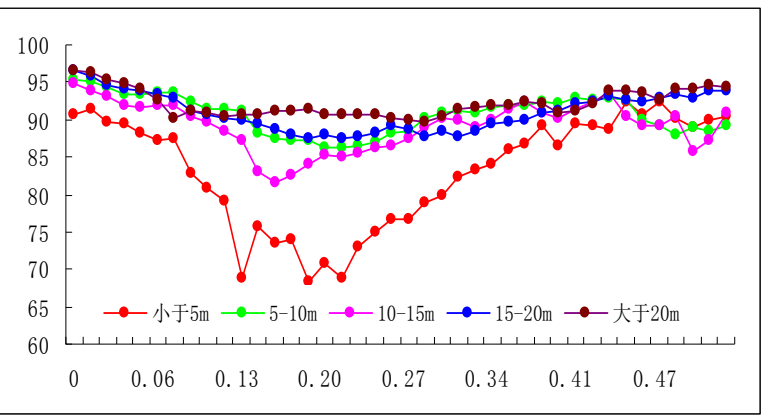

Fig.2 Layers-Recovery degree lin

Tab.1 Effective thickness classification statistics

\begin{tabular}{|c|c|c|c|c|c|c|c|}
\hline $\begin{array}{c}\text { Effective } \\
\text { thickness } \\
\text { grading }\end{array}$ & $\begin{array}{c}\text { Well } \\
\text { number }\end{array}$ & $\begin{array}{c}\text { layer } \\
\text { numbers }\end{array}$ & $\begin{array}{c}\text { average } \\
\text { thickness(m) }\end{array}$ & $\begin{array}{c}\text { average } \\
\text { effective } \\
\text { thickness } \\
(\mathrm{m})\end{array}$ & permeability( $\mu \mathrm{m} 2)$ & Water drop (\%) & $\begin{array}{c}\text { Recovery } \\
\text { degree of } \\
\text { chemical } \\
(\%)\end{array}$ \\
\hline$<5$ & 3 & 11 & 10.33 & 2.93 & 0.465 & 24.02 & 10.35 \\
\hline $5-10$ & 9 & 14.7 & 19.13 & 8.01 & 0.372 & 9.31 & 10.6 \\
\hline $10-15$ & 6 & 18.7 & 23.6 & 12.0 & 0.412 & 13.31 & 9.52 \\
\hline $15-20$ & 13 & 19.6 & 29.7 & 17.5 & 0.478 & 9.12 & 9.04 \\
\hline$>20$ & 7 & 18.6 & 33.5 & 23.4 & 0.52 & 6.79 & 9.08 \\
\hline total & 38 & 17.4 & 25.4 & 14.3 & 0.492 & 8.500 & 9.42 \\
\hline
\end{tabular}

\subsection{The Influence of Effective Thickness}

Effective thickness is the oil reservoir thickness that can be produced commercial oil in the existing economic and technical conditions . A well of water drop is bigger, even have obvious secondary effect phenomenon when its effective thickness less than $15 \mathrm{~m}$ (fig.2); The recovery degree is higher if the well's effective thickness is less than $10 \mathrm{~m}$, but a well of water drop and recovery degree is relatively small when its effective thickness is greater than $15 \mathrm{~m}$ (tab.1)

the reason: 1 a well which effective thickness is less than $15 \mathrm{~m}$, its number of layers is relatively small, that is advantageous for the development adjustment; 2 the water cut at the beginning of this part of the well is low, its remaining oil is rich, that conducive to form oil displacement of wall

\subsection{The Influence of Formation Coefficient(Kh)}

The formation coefficient is the product of effective thickness and permeability, it reflects the standard of reservoir physical property, and the capacity of reservoir' oil production or water absorption. The less of formation coefficient, the larger of its well water drop, but it is soon recovered; the formation coefficient is larger, the longer of its low water cut period, and the well recovery degree is higher. But if the coefficient is more than 8 , water drop and phase recovery degree of well group is minimal

Analysis of formation coefficient greater than 8 well group work bad reasons: 1 the well group of formation coefficient greater than 8 , its layer number is large, with high permeability and serious conflict among layers, easy to form a single dash; 2 the well water at the beginning is higher of this part wells, less residual oil

\subsection{The Influence of Permeability}

The higher of the formation permeability, the stronger the fluid percolation ability, it is an important parameter to affect reservoir producing extent. Different permeability well group of maximum water drop difference is not big. But according the picks up speed, the higher of the permeability, the faster its water picks up speed, the smaller of the permeability, the longer low water cut period of well group. There is no obvious regularity on recovery degree, That shows asp flooding can also be used in low permeability reservoir, and the reservoir improved use rate low permeability oil reservoir was significantly higher permeability reservoir in Asp flooding stage degree, it also prove the viewpoint right. (fig3) 


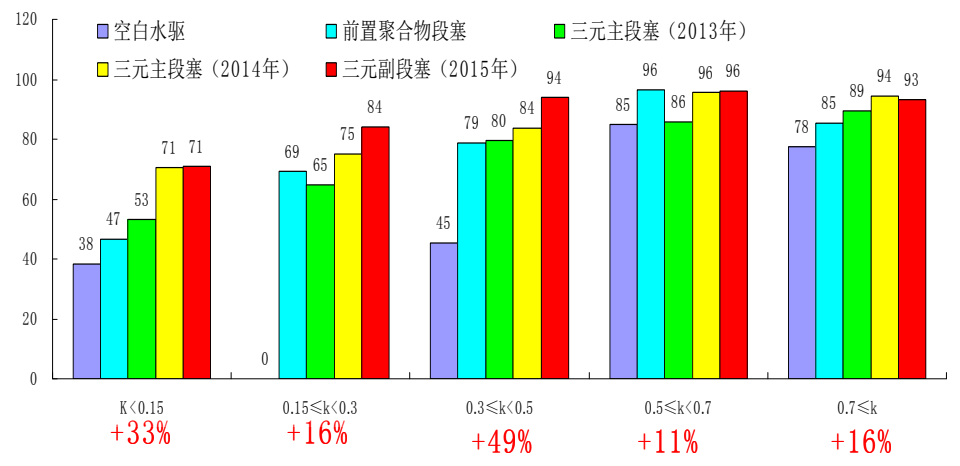

Fig. 3 the use rate of different reservoir

\subsection{The Influence of Permeability Variation Coefficient}

The permeability variation coefficient shows the reservoir heterogeneity on the longitudinal, Permeability variation coefficient may change between the range 0 to 1 , for an ideal homogeneous reservoir, its permeability variation coefficient value should be equal to zero, the limit of inhomogeneous reservoir variation coefficient is equal to 1 . The permeability variation coefficient scope of statistical well is between 0.539 to 0.782 . The line of water cut shows that ,The smaller of the permeability variation coefficient, the greater of the water drop, and have obvious secondary effect phenomenon. That proves the homogeneous reservoir is easier to drive.

\subsection{The Influence of Channel Sand(Rate of Thickness and More Further Connected)}

The biggest water drop is the wells with no channel sand, the second is the symmetry of channel sand thickness is more than $80 \%$.The more of channel sand connected well group, the greater of the water drop, but the water drop of well group without multiple connected is the largest. look from the recovery degree, the larger of multiple connected ratio, the greater the recovery degree, The main effect Asp flooding is to increase the swept volume and oil displacement efficiency , the main oil product reservoir is in channel reservoir.

\subsection{The Influence of Residual Oil (the Initial Water Cut, Recovery Degree Before Production)}

The amount of well group remaining oil directly affect the evaluation of chemical flooding displacement effect ${ }^{[15]}$. The lower of the initial water cut, the greater effect of the chemical flooding stage water drop. But according the water-cut line, the lower of recovery degree before production, the smaller of water cut decreased, The trend is the same of The chemical flooding stage recovery degree. That shows that Water flooding phase extraction difficulty remaining oil in chemical flooding stage as there is a big challenge.

The reason analysis: the less of the Residual oil, the higher the water saturation. then higher requirements for displacing fluid viscosity, the more difficult to flow control, and the more difficult it is to the displacement

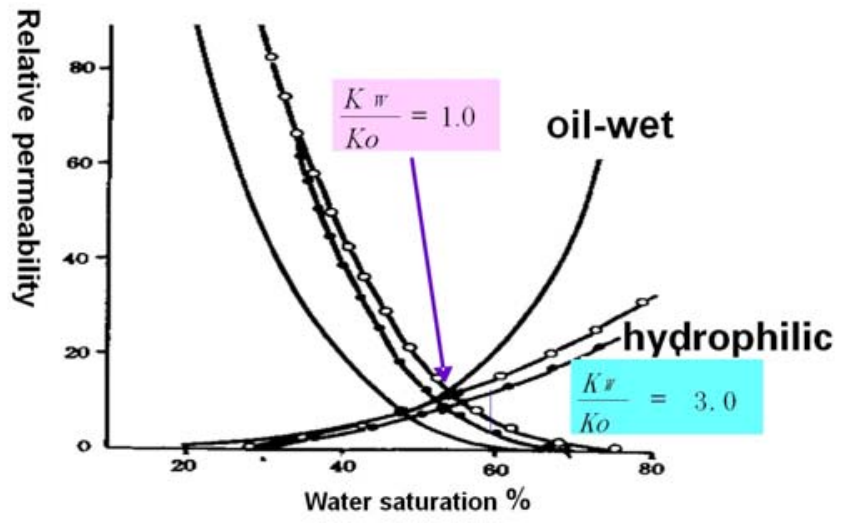

Fig.4 Different wettability of relative permeability curve and dispersed

From the fig.4, the bigger of Water saturation, the larger of Oil and water phase permeability ratio $\mathrm{KW} / \mathrm{Ko}$, and the less of Oil flow rate $\mathrm{M}$, that is conducive to the displacement. Accordingly with the increase of oil and water phase permeability ratio, displacement fluid viscosity increases accordingly, 
to maintain the stability of the oil flow rate. Displacement fluid viscosity increases, injection-production difficulty increases, increased difficulties of displacement (fig.4).

$$
\begin{aligned}
& M=\frac{\lambda_{W}}{\lambda_{o}}=\frac{K_{W}}{\mu_{W}} \cdot \frac{\mu_{0}}{K_{O}}=\frac{K_{W}}{K_{O}} \bullet \frac{\mu_{0}}{\mu_{W}} \\
& M-\text { Oil flow rate } \\
& --\lambda_{W} \text { The mobility of water } \\
& --\lambda_{O} \text { The oil mobility }
\end{aligned}
$$

\section{Conclusion}

3. 1 Different permeability well group of maximum water drop, there is no obvious regularity on recovery degree, low permeability well group low recovery degree does not necessarily explain asp flooding can also be used in low permeability reservoir. That asp flooding can also be used in low permeability reservoir.

3.2 The smaller the permeability variation coefficient, the greater the water drop, and have obvious phenomenon secondary effect, the larger the variation coefficient, the smaller the water drop, easier for homogeneous reservoir oil displacement..

3. 3 The lower the initial water cut, the chemical flooding stage water drop, the greater the effect, the more obvious, the first low recovery degree, the chemical flooding stage and a low recovery degree. Water flooding stage extraction difficult residual oil, also there is a big challenge in the chemical flooding stage.

\section{References}

[1]. Xu Jianjun, Xu Yan-chao, Yan, Li-me,et. al. Research on the method of optimal PMU placement. International Journal of Online Engineering,v9, S7, p24-29, 2013.

[2]. YAN Limei,XIE Yibing, XU Jianjun, et.al. Improved Forward and Backward Substitution in Calculation of Power Distribution Network with Distributed Generation. JOURNAL OF XI'AN JIAOTONG UNIVERSITY,2013, Vol.47, No.6, p117-123. (In Chinese).

[3]. Longchao, Zhu Jianjun, Xu; Limei, Yan. Research on congestion elimination method of circuit overload and transmission congestion in the internet of things. Multimedia Tools and Applications, p 1-20, June 27, 2016.

[4]. Xu J.J., Gai D., Yan L.M. A NEW FAULT IDENTIFICATION AND DIAGNOSIS ON PUMP VALVES OF MEDICAL RECIPROCATING PUMPS. Basic \& Clinical Pharmacology \& Toxicology, 2016,118 (Suppl. 1), 38-38.

[5]. YAN Li-mei, CUI Jia, XU Jian-jun, et.al. Power system state estimation of quadrature Kalman filter based on PMU/SCADA measurements. Electric Machines and Control. 2014, Vol.18 No.6,: 78-84. (In Chinese).

[6]. Xu Jian-Jun, Y. Y. Zi., Numerical Modeling for Enhancement of Oil Recovery via Direct Current. International Journal of Applied Mathematics and Statistics, 2013, 43(13):318-326.

[7]. Yan Limei, Zhu Yusong, Xu Jianjun,et.al. Transmission Lines Modeling Method Based on Fractional Order Calculus Theory. TRANSACTIONS OF CHINA ELECTROTECHNICAL SOCIETY, 2014, Vol.29, No. 9:260-268 (In Chinese). 